\title{
Peritaje de fallos en turbocompresores de motores de combustion interna alternativos
}

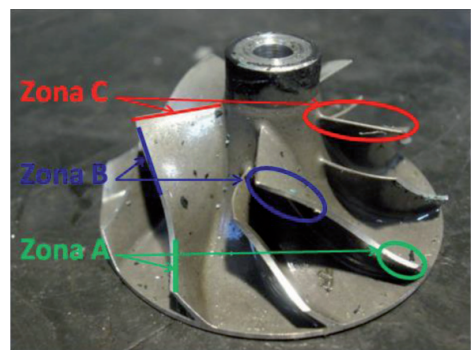

\section{Fault expertise in internal combustion engine turbocharger}

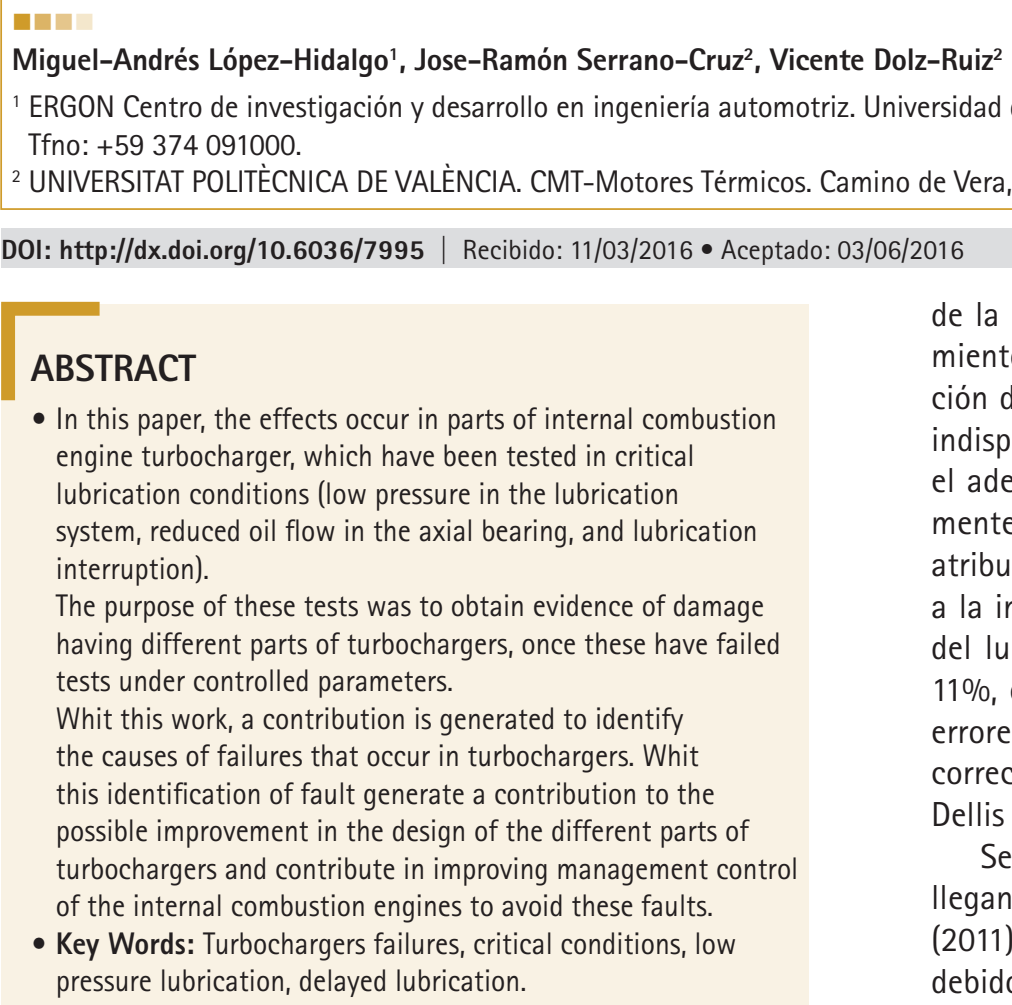

\section{ABSTRACT}

- In this paper, the effects occur in parts of internal combustion engine turbocharger, which have been tested in critical lubrication conditions (low pressure in the lubrication system, reduced oil flow in the axial bearing, and lubrication interruption).

The purpose of these tests was to obtain evidence of damage having different parts of turbochargers, once these have failed tests under controlled parameters.

Whit this work, a contribution is generated to identify the causes of failures that occur in turbochargers. Whit this identification of fault generate a contribution to the possible improvement in the design of the different parts of turbochargers and contribute in improving management control of the internal combustion engines to avoid these faults.

- Key Words: Turbochargers failures, critical conditions, low pressure lubrication, delayed lubrication. Dellis (2013) (1).

\section{RESUMEN}

En este trabajo, se presentan los efectos en las partes de turbocompresores de motores de combustión interna alternativos (MClA), que han sido ensayados en condiciones críticas de lubricación (baja presión en el sistema de lubricación, disminución de flujo de aceite en el cojinete axial, e interrupción en la lubricación).

La finalidad de estos ensayos, ha sido el de obtener evidencias de los daños que presentan las diferentes partes de los turbocompresores, una vez que estos han fallado bajo parámetros controlados de los ensayos.

Con este trabajo, se genera un aporte para identificar las causas de los fallos que se producen en turbocompresores de $\mathrm{MCI}$. Con esta identificación de los fallos se pretende generar un aporte para la posible mejora en los diseños de las diferentes partes de turbocompresores, así como aportar en la mejora de la gestión de control de los MCIA para evitar estos fallos.

Palabras Clave: Fallos en turbocompresores, condiciones críticas, baja presión de lubricación, retraso en la lubricación.

\section{INTRODUCCIÓN}

Debido a la velocidad de giro tan elevada a la que puede llegar el eje del turbocompresor (hasta $250 \mathrm{kr} / \mathrm{min}$ aproximadamente) y las temperaturas que alcanzan los gases que atraviesan la voluta de la turbina (alrededor de $900^{\circ} \mathrm{C}$ ), las condiciones de funcionamiento del turbocompresor son extremas, por lo tanto la lubricación debe cumplir con todos sus aspectos tribológicos, requisitos indispensables para que el funcionamiento del turbocompresor sea el adecuado. Los fallos en los turbocompresores están principalmente relacionados con el sistema de lubricación un 50\% (30\% es atribuido al retraso en la entrada del lubricante y $20 \%$ es atribuido a la insuficiente cantidad de lubricante), excesivo calentamiento del lubricante un 12\%, partículas presentes en el lubricante un $11 \%$, objetos extraños en las volutas un $3 \%$ y un $24 \%$ debido a errores humanos por: imperfecciones en la alineación del eje, incorrecta instalación del rotor y el uso de repuestos inadecuados,

Se han revisado los tipos de fallos en los turbocompresores, llegando a clasificar los fallos en cuatro grupos, según Lozanovic (2011) (2): a) Contaminación del aceite por presencia de partículas debido a un aceite en malas condiciones o mal filtrado, b) Falta de aceite debido a la obstrucción en el circuito de lubricación, c) Condiciones extremas de operación debido a temperaturas excesivamente altas de los gases de escape y d) Ingreso de objetos extraños que dañan los álabes del compresor y turbina. Lozanovic destaca que los cuatro grupos de fallos son causados por problemas en el motor y no por el turbocompresor. Tradicionalmente se han reportado algunos de los problemas típicos en el motor causados por el turbogrupo. Los síntomas que presentan los motores y que han sido identificados son los siguientes, según Honey Well TurboTechnologies (2009) (3):

- Problemas de rendimiento del motor por falta de compresión del turbocompresor.

- Excesivas emisiones contaminantes del motor por falta de estanqueidad en el sistema de lubricación del turbocompresor.

- Ingreso de aceite desde el compresor al sistema de admisión o salida de aceite por la turbina hacia el sistema de gases de escape.

- Incremento del ruido por vibraciones en el turbocompresor.

- Ruido proveniente del impacto del rotor con la carcasa o el silbido que produce el turbocompresor por el desbalance del eje.

Pese a tener identificada la repercusión de los fallos del turbocompresor en el motor, todavía falta generar un conocimiento claro sobre las condiciones más extremas a las que puede llegar 
a funcionar un turbocompresor, las causas de los fallos en el turbocompresor y falta identificar los mecanismos de fallo del turbocompresor.

El objetivo en este trabajo es tratar de determinar la secuencia de los mecanismos de los fallos en los turbocompresores y clarificar las condiciones críticas o límites en los cuales los turbocompresores pueden seguir en funcionamiento sin sufrir daños.

Los mecanismos de fallos y condiciones límites pueden resultar interesantes para mejorar la gestión de sistemas de control electrónico del turbocompresor, optimizar el diseño de sistemas que trabajan en conjunto con el turbocompresor, como por ejemplo el sistema de lubricación. También se pueden establecer criterios que ayuden a realizar peritajes y determinar responsabilidades sobre fallos ocurridos, de responsabilidad del motor o del turbogrupo.

\section{MATERIAL Y MÉTODOS}

\subsection{MATERIALES}

Características de los turbocompresores

Los turbocompresores utilizados en motores de combustión interna pueden tener diferentes sistemas de apoyo del eje, sin embargo, el sistema de apoyo que es más utilizado en este tipo de turbocompresores son los cojinetes de lubricación hidrodinámica y en menor medida los apoyos o cojinetes de rodamientos, Kelly (2010) (4).

En la Tabla 1 se pueden ver los tipos de turbocompresores utilizados en este trabajo. En la primera columna está la nomenclatura que se utilizará para los turbocompresores, la cual indica lo siguiente: la marca, el tipo de turbocompresor y el sistema de apoyo del eje. Dentro del sistema de apoyo se identifican tres tipos: el flotante "FRB", el semiflotante "SFRB" y un semiflotante tipo z (cojinete axial y radial en el mismo cojinete) "SFRBZ" (Figura 1).

\subsection{MÉTODO DE ENSAYO. EXPERIMENTACIÓN EN CONDICIONES CRÍTICAS DE LUBRICACIÓN}

\subsubsection{Baja presión en el sistema de lubricación}

En estos ensayos se han tratado de reproducir los efectos que se podrían presentar en el eje, en situaciones en las que la presión de alimentación de aceite es inadecuada.

El ensayo consiste en realizar aceleraciones (transitorios de régimen de giro) con un ratio comprendido entre $100 \mathrm{kr} / \mathrm{mins}$ y 500

\begin{tabular}{lccc}
\hline \hline Nomenclatura & Marca & Tipo & Sistema de apoyo \\
\hline \hline BW-GTA17-SFRB & Borg Warner & GTA1752LV & Cojinete Semiflotante \\
BW-KP35-FRB & Borg Warner & KP35 & Cojinetes Flotantes \\
BW-BV39-FRB & Borg Warner & BV39 & Cojinetes Flotantes \\
HTT-GT14-SFRBZ & Honeywell & GT14 & Cojinete Z-Semiflotante \\
\hline
\end{tabular}

Tabla 1: Tipos de turbocompresores utilizados en los ensayados $\mathrm{kr} / \mathrm{mins}$, con dos diferentes temperaturas de aceite a $90^{\circ} \mathrm{C}$ y $130^{\circ} \mathrm{C}$ y diferentes presiones de entrada del aceite al turbocompresor desde 1.5 hasta un mínimo de 1.02 bar abs.

\subsubsection{Cojinete axial con orificio de lubricación reducido}

En este ensayo se utilizó un cojinete axial con el orificio de lubricación reducido para reproducir el funcionamiento de un turbocompresor con el conducto de aceite axial obstruido. Para reproducir las condiciones más desfavorables se han realizado ensayos en los que hay tracción del eje hacia el lado del compresor, en la Figura 2 se puede observar el transitorio del motor en el que se encuentra acoplado el TC. En la Figura 3a) se puede ver una fotografía del cojinete axial con el orificio de paso de aceite normal (diámetro aproximado de $0.9 \mathrm{~mm}$ ). El diámetro de este orificio en el cojinete axial modificado ha sido reducido hasta $0.3 \mathrm{~mm}$ aproximadamente.

Para evaluar la diferencia de flujo másico de aceite, se midió el flujo con distintas presiones en los dos tipos de cojinetes. En la Figura 3b) se puede observar la diferencia de flujo másico con diferentes saltos de presiones en estos cojinetes (orificio reducido

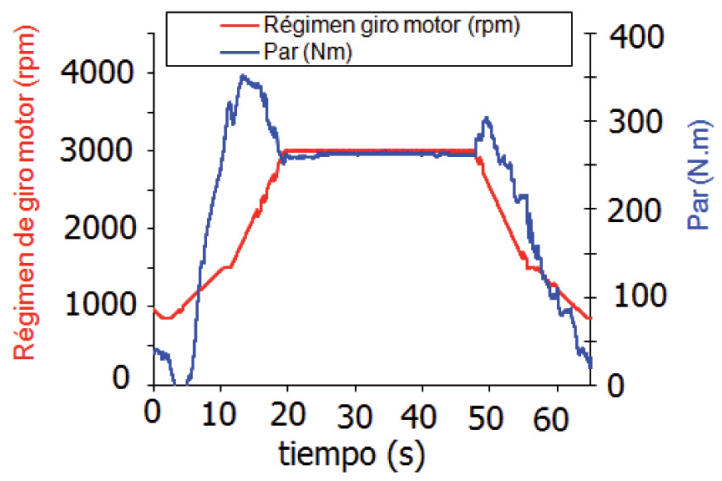

Figura 2: Transitorio de régimen de giro y carga del motor que alimenta al turbocompresor
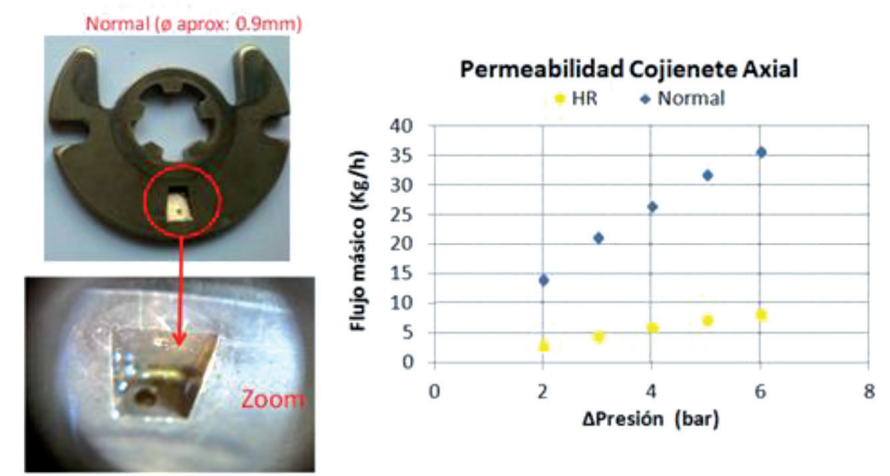

Figura 3a): Fotografía cojinete axial con orificio normal. 3b): Flujo másico cojinete orificio reducido " $\mathrm{HR}$ " y normal

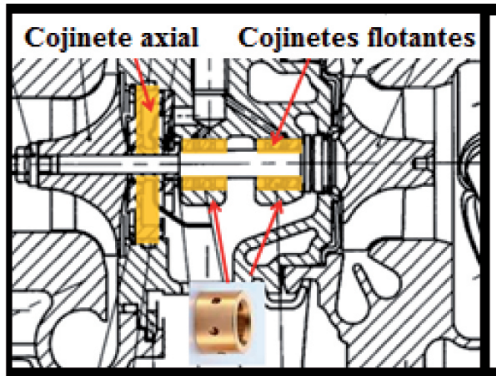

FRB

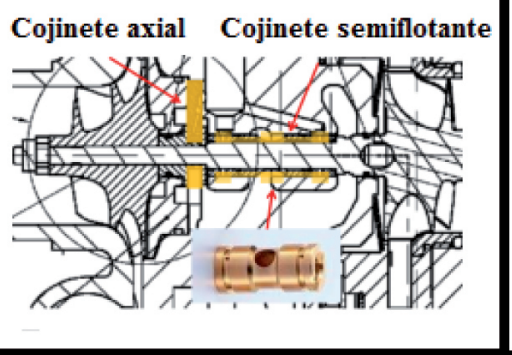

SFRB
Cojinete semiflotante tipo $\mathrm{Z}$ (radial + axial)

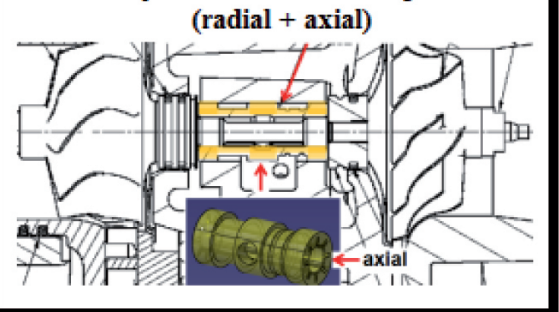

Figura 1: Turbocompresor con cojinetes flotantes "FRB", semiflotante "SFRB", semiflotante tipo Z "SFRBZ" 
y normal). En la leyenda las letras "HR" identifican el cojinete axial de orificio reducido.

\subsubsection{Interrupción de la lubricación}

En este ensayo se han realizado ciclos de corte de aceite, estos se han realizado en la entrada de aceite al sistema de lubricación del turbocompresor, cada corte de lubricación ha sido de 15 segundos y después otra vez se da paso al aceite durante 15 segundos más. Estos ciclos se han repetido 60 veces para observar los efectos de la acumulación de ciclos en pequeños cortes de lubricación, en condiciones de funcionamiento del turbocompresor estacionarias. La velocidad de giro del turbocompresor se ha mantenido constante a $150 \mathrm{kr} / \mathrm{min}$ durante estos cortes de lubricación. En este ensayo se utilizaron dos tipos de turbocompresores Borg Warner: 3 turbocompresores BW-KP35-FRB con cojinetes flotantes y 2 turbocompresores BW-GTA17-SFRB con cojinetes semiflotantes.

\section{RESULTADOS Y DISCUSIÓN}

Para identificar las causas de los problemas en el turbocompresor se han medido variables termodinámicas como la presión y temperatura en el circuito de aire, circuito de gases y lubricación del turbocompresor. También se ha medido el movimiento del eje para identificar el comportamiento del turbocompresor en el instante que presenta el fallo. Las técnicas utilizadas para la medida del movimiento del eje son detalladas por Pastor (2012) (5) técnica mediante imágenes y Serrano (2015) (6) técnica con sensores infrarrojos.

Se han determinado algunos "parámetros principales" que sirven para identificar el momento del fallo, similitudes en los daños

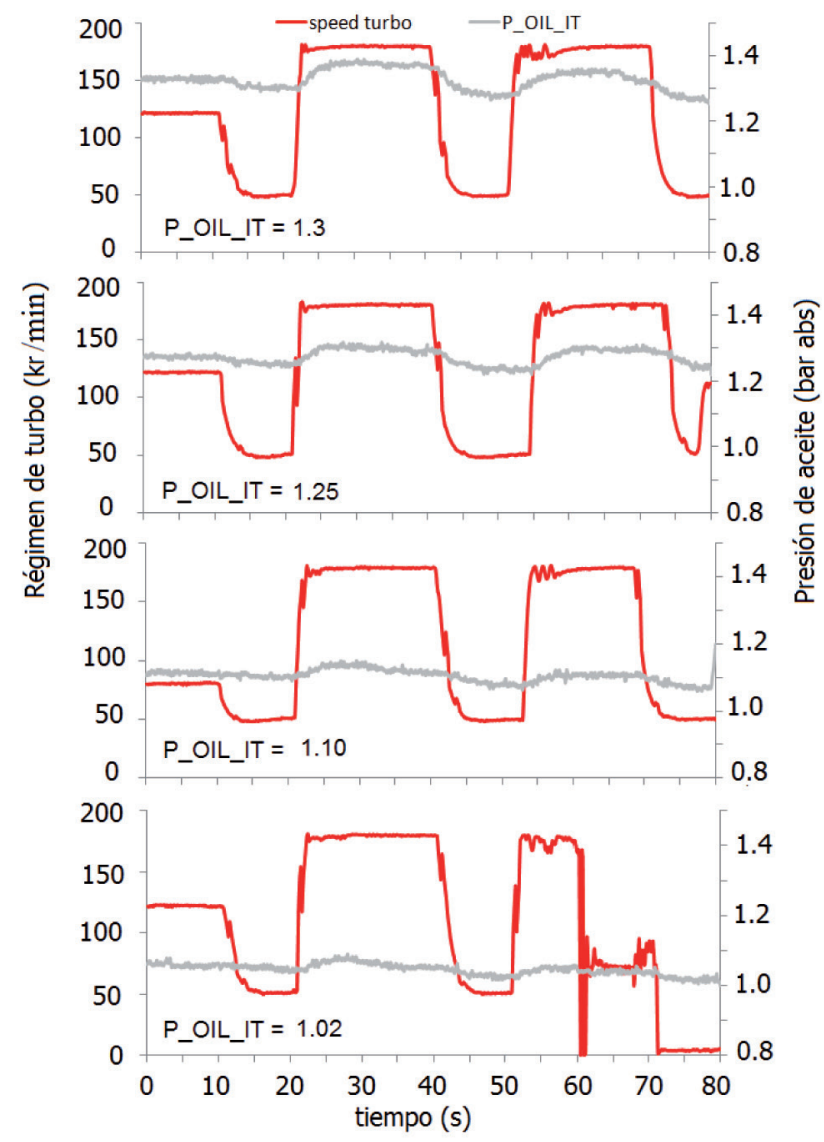

de los diferentes elementos, pautas de funcionamiento y las posibles razones para que se originen los fallos. Estos "parámetros principales" son los siguientes:

- Movimiento del eje: En esta variable se analiza el criterio de máxima excentricidad alcanzada. Este criterio es el diámetro de la órbita que describe el movimiento del eje dividido para la máxima excentricidad del turbocompresor (máximo movimiento que puede llegar a tener el eje hasta entrar en contacto con un elemento fijo), el movimiento del eje se obtuvo con la técnica de medida con imágenes. En los ensayos en los que se aplica la técnica con sensores infrarrojos se utiliza el criterio del máximo diámetro del movimiento de precesión de la punta del eje adimensionalizada (dividida) con la máxima excentricidad, como es explicado en los artículos de Pastor (2012) (5) y Serrano (2015) (6) para las técnicas, respectivamente.

- Nivel de daños observados: Al reducir la película de lubricación por carencia de aceite, se puede producir contacto entre eje y cojinete. La evidencia de este contacto en los ensayos fue la presencia de colores de temple (por aumento de temperatura), ralladuras (por desgaste abrasivo) o adición de material (por desgaste adhesivo) en el eje, en la revisión posterior a los ensayos. Los principales colores de temple observados en las revisiones han sido morado y azul, las temperaturas alcanzadas para esta coloración deben estar entre $280^{\circ} \mathrm{C}$ y $290^{\circ} \mathrm{C}$ según Verhoeven (2005) (7). También se han observado ralladuras en el eje y en los cojinetes (desgaste abrasivo), pero sin la presencia de colores de temple, es un indicador de fricción pero en instantes de tiempo muy reducidos. 
- Indicadores termodinámicos: Se han obtenido distintas variables medidas durante los ensayos para que permitan identificar variaciones en el rendimiento del turbocompresor, las variables medidas han sido: temperaturas y presiones de entrada y salida del compresor y turbina; y de entrada y salida del aceite; flujos de aire en el compresor y gases de escape en la turbina.

\section{Baja presión en el sistema de lubricación}

En estos ensayos se utilizaron 2 turbocompresores Borg Warner BW-BV39-FRB con cojinetes flotantes y un turbocompresor Honeywell HTT-GT14-SFRBZ con cojinete semiflotante. Con el primer grupo de turbocompresores (Borg Warner) se ensayó realizando dos aceleraciones (transitorios de régimen de giro) con un ratio comprendido entre $100 \mathrm{kr} / \mathrm{mins}$ y $500 \mathrm{kr} / \mathrm{mins}$, la temperatura del aceite de entrada al TC es de $90^{\circ} \mathrm{C}$ y las presiones de entrada del aceite al TC van desde 1.3 hasta un mínimo de 1.02 bar abs. Con el segundo tipo de turbocompresor (Honeywell) se realizaron ensayos con presiones de: 1.5, 1.3 y 1.1 bar abs, con ratio de aceleración de hasta $180 \mathrm{kr} / \mathrm{mins}$ y temperatura de entrada del aceite al TC de $90^{\circ} \mathrm{C}$ y $130^{\circ} \mathrm{C}$.

En la Figura 4 se presentan los resultados del ensayo con el primer TC Borg Warner BW-BV39-FRB. En la Figura 4a) se observa el régimen de giro (speed turbo) en color rojo y la presión de aceite a la entrada del TC (P_OIL_IT) en color gris; en el último ensayo con presión de aceite de 1.02 bar abs, se observa una caída en el régimen de giro del TC, en el segundo 60, en la Figura 4b) se presentan las variables termodinámicas (temperaturas en la parte superior y presiones en la parte inferior) de este ensayo con presión de 1.02 bar abs, además en el segundo 60 se puede observar un incremento de la temperatura en la salida del aceite del TC línea color verde claro (T_OIL_OT) y una pérdida de presión en la salida del compresor línea negra entrecortada (P_OC), este ensayo se realizó con un pico de aceleración de $320 \mathrm{kr} / \mathrm{mins}$.

En la Figura 5 se ven las diferentes partes del TC con las evidencias de colores de temple en el eje y la arandela del cojinete axial, las arandelas del cojinete axial resultaron soldadas entre sí, además se evidencian las ralladuras en el eje, rallas en los cojinetes radiales (se evidencian rallas externas debido a que son cojinetes flotantes) y el contacto de los álabes de la rueda del compresor con la carcasa.

Con el segundo TC marca Borg Warner BW-BV39-FRB, se incrementó el ratio de aceleración hasta $500 \mathrm{kr} / \mathrm{mins}$ y la mínima presión de entrada de aceite ensayada fue de 1.25 bar abs, pese a estas condiciones extremas el TC no presentó averías.

Con el TC Honeywell HTT-GT14-SFRBZ de cojinete flotante tipo $z$, el ensayo más crítico fue con una presión de 1.1 bar abs, ratio de aceleración de $180 \mathrm{kr} / \mathrm{mins}$ y temperatura del aceite de $130^{\circ} \mathrm{C}$.

En la Figura 6 se pueden observar los diámetros adimensionalizados de la órbita que describe el movimiento de precesión de la punta del eje en el lado del compresor. Estos datos han sido obtenidos de las señales filtradas de los sensores durante cada uno de los ensayos con la técnica de medida con sensores infrarrojos, como lo explica Serrano (2015) (6). La señal ha sido adimensionalizada con el diámetro de la máxima excentricidad del turbocompresor (máximo movimiento que podría alcanzar el eje del turbocompresor para entrar en contacto entre el eje y los cojinetes). En la leyenda de la Figura 6 se puede observar la temperatura del aceite $\left(90^{\circ} \mathrm{C}\right.$ ó $130^{\circ} \mathrm{C}$ ), la presión de entrada del aceite (1.5 ó 1.1 bar abs) y el número de ensayo (t1 o t2), cada ensayo se realizó dos veces para observar su repetitividad. Aquí se puede observar que la máxima amplitud de movimiento se alcanza con menor presión de aceite y mayor temperatura $\left(1.1\right.$ bar abs y $130^{\circ} \mathrm{C}$ ) como era de esperar, estos movimientos con líneas de color negro y violeta.

Movimiento del eje: Con el turbocompresor (HTT-GT14-SFRBZ) con cojinete semiflotante tipo $z$, pese a tener una presión en el sistema de aceite de solo 1.1 bar abs y ratios de aceleración de 180 $\mathrm{kr} / \mathrm{mins}$, solo se alcanzó un máximo de amplitud de movimiento de 0.33 en el movimiento del eje.

Nivel de daños observados. En el turbocompresor (BW-BV39FRB) el lado del compresor es el que presenta más daños, el eje no presenta colores de temple muy perceptibles, las arandelas del cojinete axial están soldadas entre sí y presentan colores de temple, los cojinetes radiales tienen ralladuras muy profundas, la turbina no presenta daños muy graves (fotografías Figura 5).

Indicadores termodinámicos. Se ve un aumento en la temperatura de salida del aceite de $80^{\circ} \mathrm{C}$ aproximadamente, para este incremento de temperatura se plantean dos hipótesis: a) El aumento de temperatura en la salida del aceite (T_OIL_OT) puede ser un indicador de pérdida de estanqueidad en el lado de la turbina (incremento de blow by de los gases de escape al sistema de lubricación del TC), además se observa que el compresor sigue comprimiendo pero con pérdidas de presión y la turbina disminuye su rendimiento tiene un incremento súbito de temperatura a la salida de turbina de $26^{\circ} \mathrm{C}$ aproximadamente. b) El gripaje de los cojinetes genera calor, por lo tanto se da el aumento de temperatura. Ello, junto con el roce del compresor produce una reducción en la velocidad de la turbina y por lo tanto una reducción del rendimiento de la misma, un aumento de la temperatura de salida de gases y una reducción de la relación de compresión del compresor.

Cojinete axial con orificio de lubricación reducido

Con el turbocompresor BorgWarner BW-BV39-FRB de cojinetes flotantes, se realizaron 13 horas de estabilización en es-

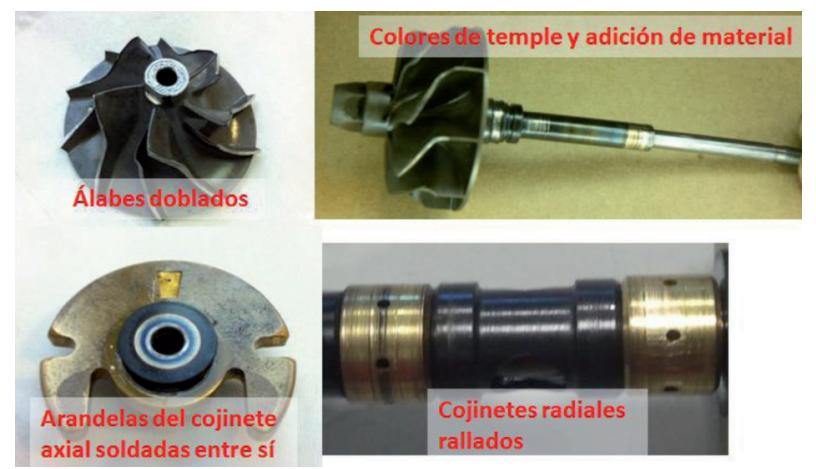

Figura 5: Fotografías turbocompresor BW-BV39-FRB, ensayos a baja presión con alto ratio de aceleración

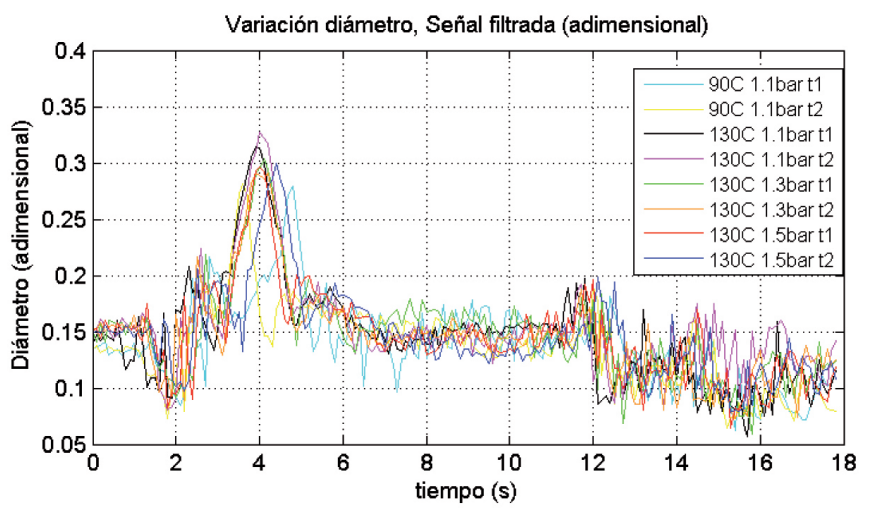

Figura 6: Señal filtrada de los sensores infrarrojos turbocompresor HTT-GT14SFRBZ, ensayos baja presión alto ratio de aceleración 
tacionario y 25 horas de los ciclos transitorios en las condiciones descritas en el apartado 2.1.2.

Debido a los ciclos repetidos de tracción del eje a los que el turbocompresor fue sometido durante los ensayos, el anillo de estanqueidad del lado de la turbina sufrió daños severos. En la Figura 7a) se puede ver el cojinete axial y dos anillos, el anillo ensayado y un anillo nuevo. Al fallar el anillo los gases del lado de la turbina pueden ingresar en el circuito de lubricación, en la Figura 7b) se puede ver un incremento de la temperatura (pico de color verde oscuro, segundo 62) en el circuito de lubricación, esto produce una ineficiente película de lubricación presentado los fallos de lubricación en el turbocompresor.

Movimiento del eje: En este ensayo no se midió el movimiento radial del eje, ya que en este ensayo el movimiento principal era axial.

a)
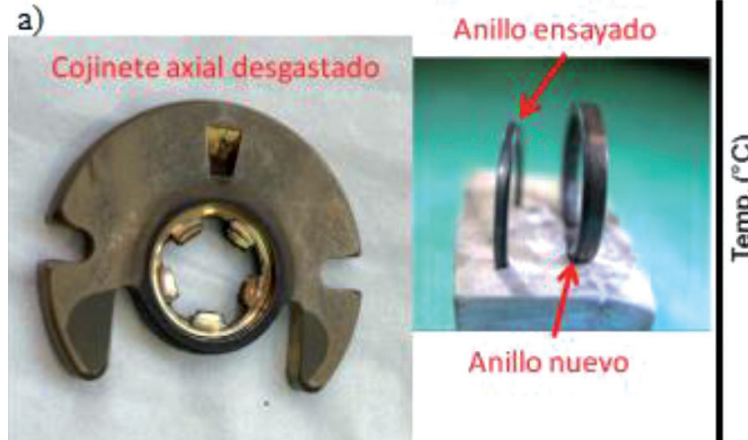

- Disminución del flujo másico en el compresor (M_COMP).

- Incremento en la temperatura del aceite de salida (T_OIL_ OT).

- En cuanto al movimiento del eje, de manera cualitativa se observó un comportamiento repetitivo. Cuando está con aceite, el movimiento describe una elipse grande y cuando está sin aceite el movimiento es más centrado en una zona pequeña.

En la Figura 9 (ANEXO 1) se pueden ver las fotografías de las distintas partes del turbocompresor que presentan anomalias después del ensayo de interrupción en la lubricación. En la parte superior se observa la adición de material del cojinete axial sobre la parte posterior de la rueda del compresor y sobre la arandela del lado del compresor. En la parte central de la Figura 9 (ANEXO 1) se

Figura 7a) Cojinete axial y anillo de estanqueidad. 7b) Variables termodinámicas ensayo orificio reducido BW-BV39-FRB
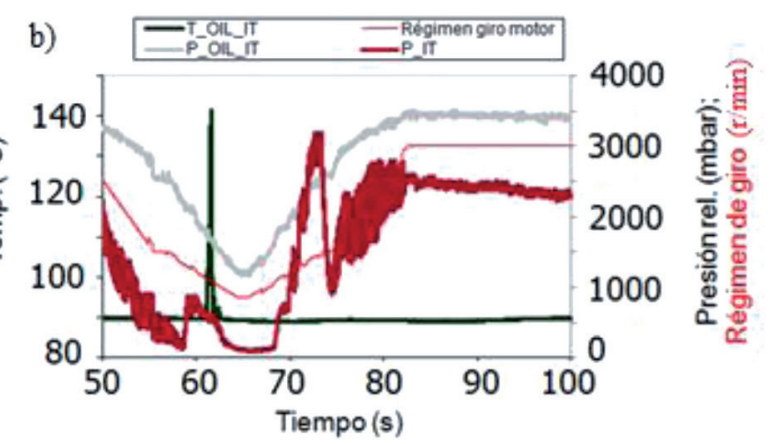

Daños observados: Se evidenciaron daños en las puntas de los álabes de la rueda del compresor (en el exducer), debido al impacto por el excesivo movimiento axial del eje. También se evidenciaron ralladuras en el cojinete axial en el lado de la turbina (es decir se produce una tracción desde el compresor), otro elemento que presentó averías fue el anillo de estanqueidad de la turbina, en la Figura 7a) se compara un anillo nuevo con el anillo ensayado.

Indicadores termodinámicos: Se observó un pico de $50^{\circ} \mathrm{C}$ de temperatura en la entrada de aceite (la hipótesis consiste en que la temperatura sube por el ingreso de gases de escape en el sistema de lubricación por el daño del anillo). El aumento de blow by en el TC, provocó el aumento de presión en el sistema de lubricación, esto produjo no solo daños en el turbogrupo sino también daños en el motor de combustión en el que se encontraba instalado el TC.

\section{Interrupción de la lubricación}

Con dos de los tres turbocompresores BWKP35-FRB se observó un comportamiento anómalo durante los ensayos. Con el primer TC se observó este comportamiento anómalo entre el segundo 250 y 500 aproximadamente (Figura 8), en esta figura se pueden observar las variables de presión y temperatura y este comportamiento anómalo tiene las siguientes características:

- Aumenta la permeabilidad del circuito de aceite, la media de los picos de la presión de entrada de aceite (P_OIL_IT) al turbocompresor son inferiores.

- Disminución de la presión a la salida compresor (P_OC). pueden ver las ralladuras en el cojinete axial, siendo las más notables las del lado del compresor. En la parte inferior de la Figura 9 (ANEXO 1) se pueden observar los colores de temple en el eje del turbocompresor específicamente en la zona de apoyo del eje sobre el cojinete (en el lado de la turbina).

Además, se utilizaron dos turbocompresores BW-GTA17-SFRB (con cojinetes semiflotantes), los dos turbocompresores tuvieron fallos en el primer corte de lubricación. Los dos turbocompresores rompieron el eje durante el ensayo. Antes de la rotura total del

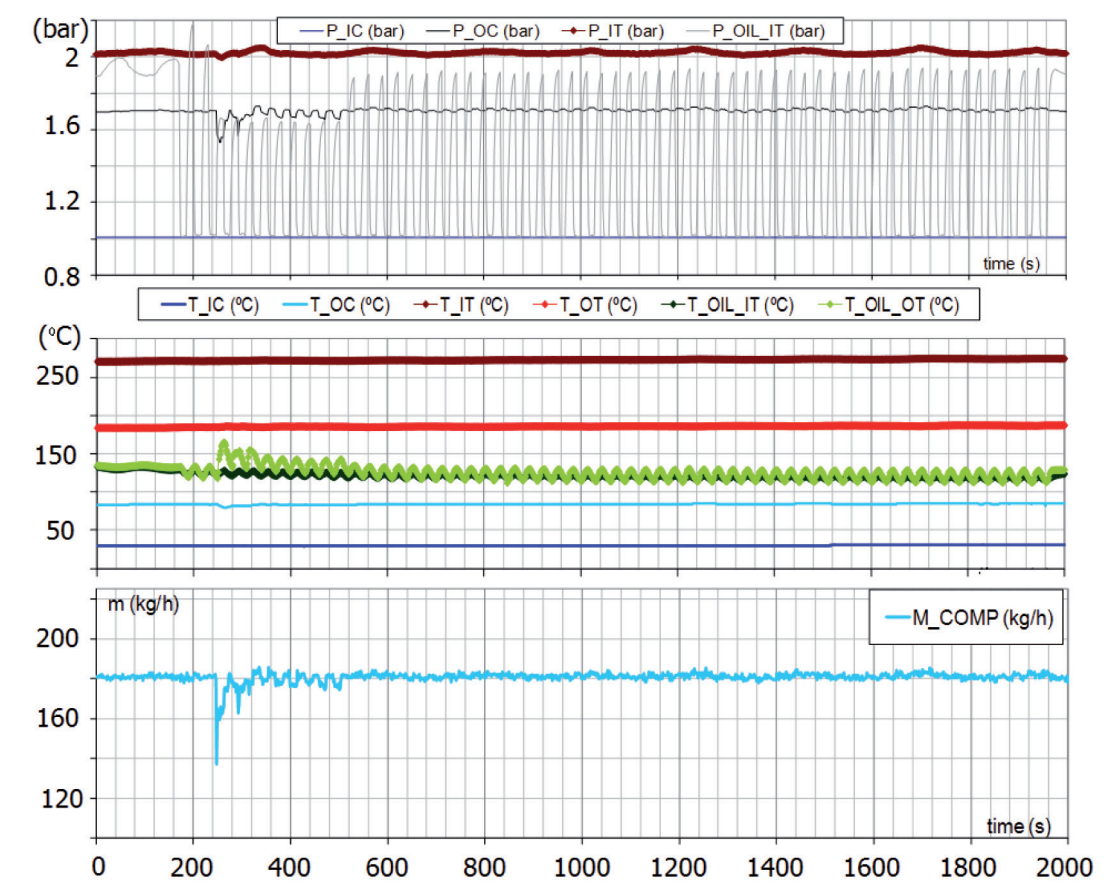

Figura 8: Variables termodinámicas durante el ensayo del primer turbocompresor BW-KP35-FRB 
turbocompresor se verificó un aumento de movimiento del radial del eje, alcanzando los límites de movimiento de máxima excentricidad. En la Figura 10 (ANEXO 1) se pueden observar los elementos del segundo TC de este tipo con sus averías, el primer TC presentó daños similares.

Movimiento del eje. El turbocompresor de cojinetes flotantes que presentó anomalías en su funcionamiento alcanzó valores de 71\% de máxima excentricidad. Uno de los turbocompresores con cojinetes semiflotantes alcanzó el 100\% de máxima excentricidad, con el segundo TC de cojinetes semiflotantes se obtuvieron datos hasta el inicio de un movimiento errático (momento en el que no se pueden procesar las imágenes para obtener la posición del eje) con medidas de hasta el 64\% de máxima excentricidad. Al revisar las imágenes del movimiento errático se observó que la amplitud de movimiento aumentó hasta alcanzar la máxima excentricidad.

Daños observados. En los turbocompresores que no rompieron pero presentaron comportamientos anómalos se observan colores de temple en los ejes (debido al largo período de tiempo con cortes de lubricación), en la Figura 10 (ANEXO 1) se ven estos colores de temple del eje. Las ralladuras en los cojinetes axiales son en el lado del compresor (es decir, se generó mayor tracción desde la turbina). Se observó que los ejes de los turbocompresores BW-GTA17SFRB se fracturaron, es posible que por aumento de los esfuerzos de torsión Figura 10 (ANEXO 1).

Indicadores termodinámicos. En los cuatro turbocompresores con problemas se observó un incremento brusco en la temperatura de aceite a la salida del TC, pero solo en los turbocompresores destruidos se observó el incremento de temperatura en la salida de la turbina.

\section{CONCLUSIONES}

Ensayos con baja presión de aceite: La primera hipótesis es que en condiciones de baja presión de aceite los TC con cojinetes semiflotantes pueden ser más resistentes que los turbocompresores de cojinetes flotantes. Esta hipótesis está fundamentada en el mayor tiempo de residencia que puede tener el aceite en el caso de TC con cojinetes semiflotantes a igualdad de condiciones de operación, estos comparados con TC de cojinetes flotantes. En el caso de no presencia de aceite se plantea una segunda hipótesis, que los TC con cojinetes flotantes parecen ser más resistentes esto debido al menor par de fricción (menor velocidad relativa entre eje y cojinete) y por lo tanto menor esfuerzo de torsión.

Cojinete axial reducido: Con este tipo de ensayos se ha podido evidenciar que en el caso de darse una deficiencia en la lubricación axial, se pueden presentar picos de temperatura en la salida de la turbina, esto debido al deterioro del anillo de estanqueidad. Este parámetro puede servir como una alarma de control en el funcionamiento del TC.

Interrupción en la lubricación: Con cortes repetitivos de aceite y contacto entre eje y cojinete, estas condiciones podrian resultar más perjudiciales para los turbocompresores con cojinetes semiflotantes. Esta hipótesis se la plantea debido a la mayor velocidad relativa entre eje y cojinete; y por lo tanto una vez que entran en contacto estos dos elementos, el eje puede sufrir un mayor esfuerzo de torsión, provocando su rotura.

En la Tabla 2 se presenta un resumen de la sensibilidad (en forma cualitativa) de los turbocompresores a las condiciones críticas de funcionamiento estudiadas en este trabajo. Con signo positivo "+" están los turbocompresores con mayor sensibilidad al tipo de ensayo y con signo negativo "-" los turbocompresores que tienen menor sensibilidad, es decir los que resisten más en ese tipo de condiciones críticas de funcionamiento. En el ensayo de cojinete axial reducido no se realizó el ensayo con el TC de cojinete semiflotante $Z$ debido a que no se puede obstruir ese cojinete.

\begin{tabular}{|l|c|c|c|}
\cline { 2 - 4 } \multicolumn{1}{c|}{} & \multicolumn{3}{|c|}{ Sensibilidad a condiciones críticas de funcionamiento } \\
\cline { 2 - 4 } & Baja presión & $\begin{array}{c}\text { Cojinete axial con } \\
\text { orificio reducido }\end{array}$ & $\begin{array}{c}\text { Interrupción en la } \\
\text { lubricación }\end{array}$ \\
\hline Cojinete flotante & + & + & - \\
\hline Cojinete semiflotante & - & $s / r$ & + \\
\hline
\end{tabular}

Tabla 2: Resumen de la sensibilidad cualitativa de los turbocompresores en diferentes condiciones criticas de funcionamiento

Peritajes: En caso de controversias entre fabricantes de motores y fabricantes de turbocompresores, sobre responsabilidad de fallos, se pueden utilizar algunos criterios observados en este trabajo:

- Colores de temple en el eje del turbocompresor: es un indicador de un fallo de cortes intermitentes de la lubricación (interrupción de la lubricación) durante lapsos de tiempo elevado.

- Presencia de ralladuras sin colores de temple en el eje: es un indicador de fallo súbito y sin presencia de aceite.

- Zonas de averías en los álabes: se han identificado tres zonas en los álabes de la rueda del compresor que pueden ser dañadas por diferentes causas. En la Figura 11 (Anexo 1) se presenta una fotografía en la que se pueden ver estas zonas:

Zona A: Daños por excesivo movimiento axial que puede ser provocado por disminución en flujo del aceite por el cojinete axial y ciclos de aceleración repetitivos.

Zona B: Daños por excesivo movimiento radial por fallos en la lubricación de los cojinetes radiales.

Zona C: Esta zona de los álabes no puede ser afectada por fallos en el sistema de lubricación o por fallos propios del turbocompresor (ningún turbocompresor en este trabajo ha presentado daños en esta zona). Esta zona solo puede verse afectada por el ingreso de objetos extraños al turbocompresor Serrano (2011) (8).

\section{BIBLIOGRAFÍA}

(1) Dellis Polichronis, Retzios Evaggelos, Geralis Alcibiades, Gasparakis Elias y Pesiridis Apostolos. "Turbocharger Lubrication - Lubricant Behaviour and Factors That Cause Turbocharger Failure". International Journal of Automotive Engineering and Technologies, Vol. 2, pp. 40-54, 2013. DOI: http://ijaet.academicpaper.org/article/view/1072000033

(2) Lozanovic Jasmina y Lozanovic Veljko. "Damage Analysis of Automotive Turbochargers". IMEKO TC15 - Experimental Mechanics- 10 th YSESMChemnitz, Germany, 2011. http://www.imeko.org/publications/ysesm-2011/ IMEKO-YSESM-2011-ea27.pdf

(3) Technologies Honeywell Turbo. "Turbo Fundamentals". EMEA Aftermarket Press Event, 2009. http://turboexchangecpt.co.za/images/2\%20turbo\%20 fundamentals.pdf

(4) Kelly A. D. "Rotordynamic characterization and comparison of Turbocharger bearing systems". Borg Warner Turbo and Emissions Systems, USA, 2010.

(5) Pastor, J.V., Serrano, J.R., Dolz, V., López, M.A., Bouffaud, F.. Study of turbocharger shaft motion by means of non-invasive optical techniques: Application to the behaviour analysis in turbocharger lubrication failures. MECHANICAL SYSTEMS AND SIGNAL PROCESSING. 32, pp. 292 - 305. 2012 DOI: http://dx.doi.org/10.1016/j.ymssp.2012.04.020

(6) J.R. Serrano, C. Guardiola, V. Dolz, M.A. López, F. Bouffaud. Study of the turbocharger shaft motion by means of infrared sensors. Mechanical Systems and Signal Processing. 56-57, pp. 246-258. 2015. DOI: http://dx.doi. org/10.1016/j.ymssp.2014.11.006

(7) Verhoeven John D. Metallurgy of Steel for Bladesmiths \& Others who Heat Treat and Forge Steel. lowa University, 2005. http://www.hybridburners.com/ documents/verhoeven.pdf

(8) Serrano J.R., Tormos B., Gargar K.L. and Bouffaud F. Study of the effects on turbocharger performance generated by the presence of foreign 
objects at the compressor intake. Experimental Techniques (2011) Society for experimental Mechanics. DOl: http://dx.doi.org/10.1111/j.17471567.2011.00795.x

\section{AGRADECIMIENTOS}

El presente estudio ha sido desarrollado gracias al apoyo de las becas del Senescyt del gobierno ecuatoriano. Y gracias a la colaboración del grupo de investigadores del departamento de motores térmicos de la Universidad Politécnica de Valencia.

\section{ANEXO 1}

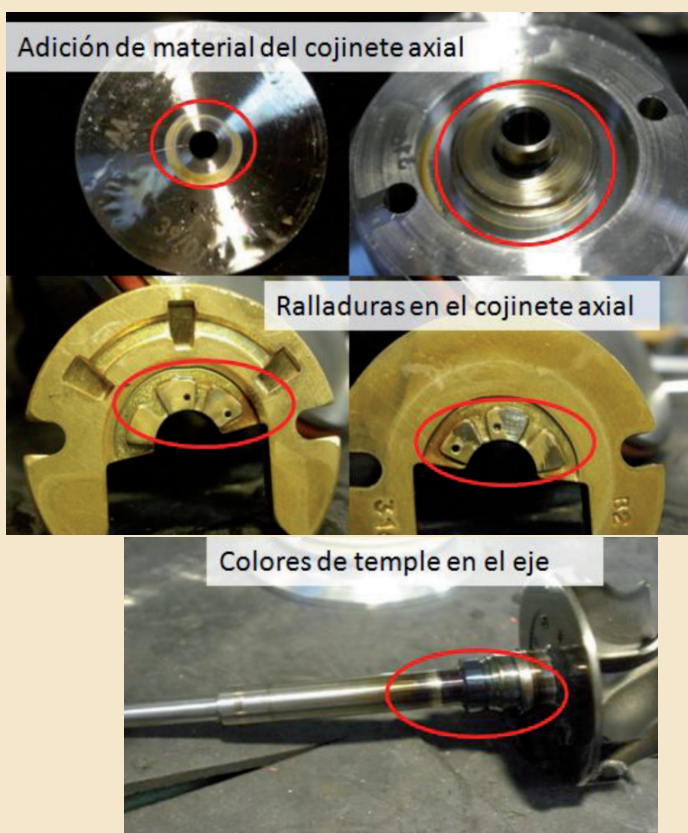

Figura 9. Fotografías de las partes del primer turbocompresor BW-KP35FRB, ensayo interrupción de lubricación

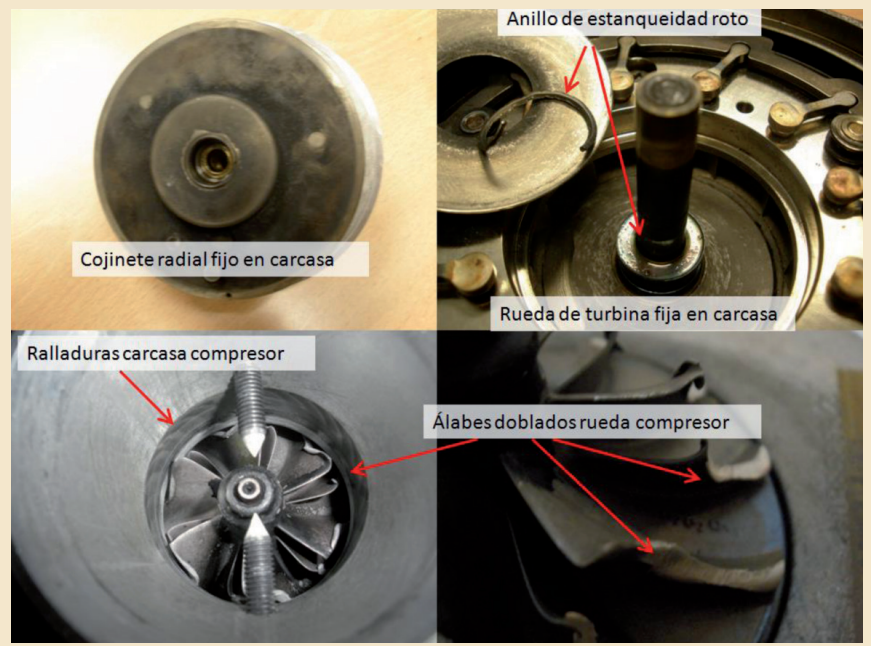

Figura 10. Fotografías de las piezas del segundo turbocompresor BWGTA17SFRB, ensayo interrupción de lubricación

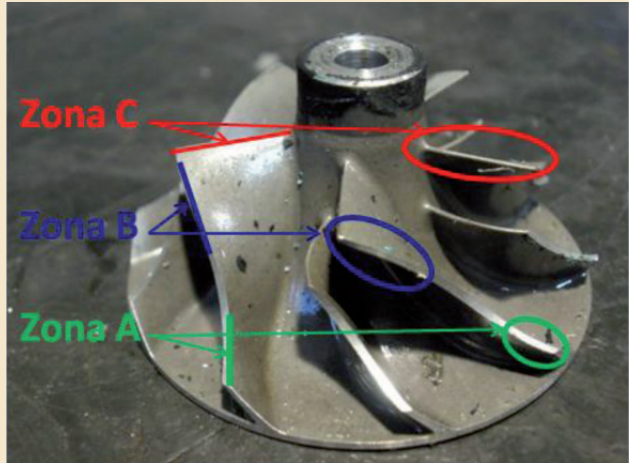

Figura 11. Zonas de averias en ruedas de compresor

\section{UNIDADES Y NOMENCLATURA}

abs

$B W$

FRB

$H T T$

$H R$

MCIA

$M$ COMP

$P$ IC

$P$ OC

P_IT

P_OT

P_OIL_IT

$S F R B$

SFRBZ

TC

T_IC

T_OC

TIIT

$T$ OT

T_OIL_IT

TOIL OT presión absoluta

Borg Warner

cojinete flotante

Honey Well

cojinete axial con orificio reducido motor de combustión interna alternativo flujo másico de aire en el compresor presión en la entrada del compresor presión en la salida del compresor presión en la entrada de la turbina presión en la salida de la turbina presión de aceite de entrada al turbocompresor

cojinete semiflotante

cojinete tipo Z, cojinete flotante y radial en el mismo cojinete turbocompresor temperatura de entrada en el compresor temperatura en la salida del compresor temperatura en la entrada de la turbina temperatura en la salida de la turbina temperatura en la entrada del aceite del turbocompresor

temperatura en la salida del aceite del turbocompresor 